\title{
ETILENO GLICOL NA CRIOPRESERVAÇÃO DE SÊMEN CANINO
}

\author{
ETHYLENE GLYCOL ON CANINE SEMEN CRYOPRESERVATON
}

\author{
Marcio Pereira Soares ${ }^{1}$ Carlos Augusto Rigon Rossi ${ }^{1}$ \\ Alceu Mezzalira ${ }^{2}$ Marcelo Cecim ${ }^{3}$
}

\section{RESUMO}

\begin{abstract}
O objetivo deste trabalho foi avaliar a utilização do etileno glicol, adicionado ao meio Tris-gema, na criopreservação de sêmen canino, considerando os seus efeitos sobre a motilidade, o vigor e a morfologia espermática pré e póscongelamento. Como doadores, utilizaram-se quatro cães da raça Pastor Alemão coletados por manipulação digital os quais no ejaculado apresentaram padrões mínimos de $90 \%$ de motilidade, cinco de vigor espermático (0 - 5) e no máximo $35 \%$ de defeitos morfológicos totais. As concentrações de etileno glicol testadas foram de 0, 25; 0,5 e 1,0M, sendo empregados como controle $0,8 M$ de glicerol. Foram feitas cinco avaliações de motilidade e vigor, respectivamente, na obtenção da fração rica, depois da primeira diluição, ao atingir $4^{\circ} \mathrm{C}$, após uma hora de estabilização a $4^{\circ} \mathrm{C}$ e no descongelamento. Avaliou-se a morfologia espermática em sêmen a fresco e após o descongelamento das amostras de cada tratamento. Não houve diferença na motilidade e na morfologia espermática dos grupos após o descongelamento. No vigor espermático pós- descongelamento, as concentrações de 0,25 e 0,5M de etileno glicol foram semelhantes entre si e com a concentração de 0,8M de glicerol (controle), mas diferiram da concentração de $1 M$, a qual apresentou vigor inferior ao controle. Conclui-se que, para a criopreservação de sêmen canino, o glicerol 0,8M pode ser substituído pelo etileno glicol nas concentrações de 0,25, 0,5 e 1,0M.
\end{abstract}

Palavras-chave: sêmen, cão, congelamento, etileno glicol.

\section{SUMMARY}

The objective of the present work was to evaluate the efficiency of ethylene glycol on criopreservation of canine semen, considering its possible deleterious effects upon semen motility, vigor and morphology at the pre and post freezing stages, using a tris-egg yolk extender. Four adult german shepards were used as donors. Samples were obtained by digital manipulation, and only ejaculates presenting a minimum of $90 \%$ motility and 5 (0-5) vigor and no more than $35 \%$ of total morphological defects were considered. Ethylene glycol concentrations tested were 0.25, 0.50 and $1.0 \mathrm{M}$ and $0.80 \mathrm{M}$ glycerol served as control. Motility and vigor were evaluated in the rich fraction, after first and second dilution, after 1 hour of stabilization at $4^{\circ} \mathrm{C}$ and after thawing. Sperm morphology was examined in the fresh sample and after thawing in each of the treatments. There were no detectable differences among the groups in sperm motility and morphology after thawing. There were no differences in vigor among the 0.25 , $0.50 \mathrm{M}$ ethylene glycol and the $0.8 \mathrm{M}$ glycerol, but the $1 \mathrm{M}$ ethylene glycol had lower vigor scores after thawing. We conclude that ethylene glycol can be used as a cryoprotectant in the concentration of $0.25,0.50$ and $1.0 \mathrm{M}$ instead of glycerol.

Key Words: semen, dog, freezen, ethylene glycol.

\section{INTRODUÇÃO}

Desde o início, as biotécnicas de reprodução assistida foram direcionadas para espécies de interesse econômico, sendo que espécies de pequeno porte só adquiriram maior expressão com o crescimento da relação sentimental entre homem e animal. A possibilidade de intercâmbio de material genético e a preservação de gametas dessas espécies de valor sentimental, como os cães de companhia, bem como de outros economicamente

\footnotetext{
${ }^{1}$ Médico Veterinário, Aluno do Programa de Pós-graduação (Mestrado) em Medicina Veterinária da Universidade Federal de Santa Maria (UFSM).

${ }^{2}$ Professor do Centro de Ciências Agroveterinárias da Universidade Estadual de Santa Catarina, Lages, SC.

${ }^{3}$ Professor Adjunto, PhD., Departamento de Clínica de Grandes Animais, Centro de Ciências Rurais, UFSM, 97105-900, Santa Maria, RS. E-mail: mcecim@lince.hcv.ufsm.br. Autor para correspondência.
} 
importantes, como a Raposa Azul (Alopes lagopogus) e a Raposa Prateada (Vulpes vulpes), portadores de genes mutantes de alto valor comercial para a indústria de curtume européia, com a preservação de animais da fauna brasileira em risco de extinção, como o Lobo Guará Brasileiro (Chrysocyon brachyurus) e a Raposinha do Campo (Pseudalopex sp.), têm suscitado a necessidade de estabelecimento de um eficiente protocolo para a criopreservação de sêmen canino (FARSTAD, 1996).

O primeiro congelamento de sêmen canino foi notificado em 1954 por Rowson e, no ano de 1969, Seager obteve a primeira prenhez com sêmen criopreservado. Desde então, diversas pesquisas foram empreendidas, a fim de se determinarem métodos de preservação de espermatozóides caninos por congelamento (ENGLAND \& PONZIO, 1996). Atualmente, as taxas de concepção, utilizando-se sêmen congelado, oscilam entre 67 e $80 \%$, as quais são obtidas através da deposição intra-uterina, com uma concentração de 50 a 150 milhões de espermatozóides, por inseminação, sendo empregadas duas inseminações, com um intervalo de 24 horas (FARSTAD, 2000).

Os diluidores utilizados para $\mathrm{o}$ resfriamento e congelamento de espermatozóides de cães foram adaptados de outras espécies (FASTARD, 1996), sendo inicialmente empregados meios à base de leite desnatado, lactose-gema, citrato-gema, tris-gema, entre outros. Atualmente, a maioria dos pesquisadores que trabalham com criopreservação de sêmen canino empregam diluidores à base de Tris e/ou citrato de sódio, com um açúcar como frutose, glicose ou lactose mais gema de ovo, associado ao crioprotetor glicerol em diferentes concentrações (RODRIGUES \& RODRIGUES, 1998).

O glicerol é o crioprotetor mais usado no congelamento de sêmen nas espécies domésticas (FARSTAD, 1996). Entretanto, seus efeitos deletérios sobre os espermatozóides são relatados por McLAUGHLIN et al. (1992), e ocorrem, provavelmente, pelas alterações causadas na sua membrana plasmática do espermatozóide (HAMMERSTEDT \& GRAHAN, 1992).

Com a evolução da biotecnologia, outros crioprotetores foram estudados. Dentre os menos tóxicos, encontra-se o etileno glicol. PLATOV (1965), congelando sêmen ovino, obteve resultados semelhantes no congelamento com $0,47 \mathrm{M}$ de glicerol e etileno glicol nas concentrações de 0,27 e $0,36 \mathrm{M}$, observando, porém, efeito negativo com a concentração de $0,89 \mathrm{M}$ de etileno glicol. SALAMON \& MAXWELL (1995), ao congelarem sêmen ovino em pellets, determinaram que o etileno glicol foi superior ao glicerol nas concentrações de 0,31 e $0,63 \mathrm{M}$, sendo que os melhores resultados foram obtidos com 0,27M de etileno glicol. MORAES et al. (1998), quando congelaram sêmen ovino em pellets, concluíram que $0,5 \mathrm{M}$ de etileno glicol proporcionou motilidade e vigor semelhantes a 0,72M de glicerol, porém com uma melhor proteção acrossomática. MERCANTE et al. (1995) compararam a eficiência dos dois crioprotetores em sêmen eqüino, verificando uma melhor performance do etileno glicol tanto com relação à motilidade e ao vigor quanto no teste de termo-resistência. NEVES NETO et al. (1995), comparando o glicerol ao etileno glicol, obtiveram maiores índices de prenhez com sêmen eqüino congelado com etileno glicol. Já ALVARENGA et al. (2000) não observaram diferenças entre o glicerol e etileno glicol na criopreservação de sêmen eqüino.

O objetivo do presente trabalho foi avaliar a capacidade crioprotetora do etileno glicol em diluente Tris-gema na manutenção da motilidade, do vigor e da morfologia espermática do sêmen canino.

\section{MATERIAL E MÉTODO}

Como doadores de sêmen, utilizaram-se quatro cães da raça Pastor Alemão, com idade média de 3,6 anos, pertencentes ao Canil Vento Divino da Base Aérea de Santa Maria (BASM). Todos os animais foram submetidos ao mesmo manejo sanitário e alimentar, recebendo ração comercial uma vez ao dia e água ad libitum. As coletas de sêmen foram realizadas através da técnica de manipulação digital, com observação das três fases da ejaculação e seleção da segunda fração, rica em espermatozóides (CHRISTIANSEN, 1986). Foram realizadas duas coletas em média por semana, entre os meses de outubro e novembro. Após a coleta, os ejaculados foram mantidos a $27^{\circ} \mathrm{C}$ em banho-maria durante a sua avaliação. Foram utilizados para congelação somente os ejaculados com padrões mínimos de $90 \%$ de motilidade progressiva, vigor espermático 5 na escala de PLATZ \& SEAGER (1977) e com, no máximo, 35\% de defeitos morfológicos totais. Para a determinação das concentrações espermáticas utilizou-se (x106/mm3) câmara hematimétrica, diluição 1:100 em solução de formol-citrato a $4 \%$, microscopia ótica, com objetiva de aumento de 400X (FELDMAN \& NELSON, 
1996). As alterações morfológicas foram classificadas em primárias e secundárias (SEAGER, 1986).

$\begin{array}{ccccc} & \text { O diluidor usado foi o Tris-gema, } \\ \text { composto } & \text { por } & 3,028 \mathrm{~g} & \text { de } & \text { Tris }\end{array}$ (trimethylhydroxyaminomethane) (acrescido de $1,75 \mathrm{~g}$ de ácido cítrico monohidrato, $1,25 \mathrm{~g}$ de $\mathrm{D}$ frutose diluídos em 100ml (qsp) de água destilada (RODRIGUES \& RODRIGUES, 1998) e 20\% de gema de ovo (diluidor I). A partir do diluidor I, constituiu-se o diluidor II pela adição dos crioprotetores de acordo com os tratamentos, sendo testadas as concentrações de 0,25; 0,5 e $1 \mathrm{M}$ de etileno glicol $^{\mathrm{a}}$ e $0,8 \mathrm{M}$ de gicerol $^{\mathrm{a}}$ (controle).

Os ejaculados considerados aptos foram diluídos inicialmente pela adição do diluidor I a $27^{\circ} \mathrm{C}$ na proporção de duas partes de diluente para uma parte do ejaculado, seguindo-se da segunda avaliação da motilidade e vigor espermático e do início do resfriamento em água com gelo. Ao atingir a temperatura de $4,0^{\circ} \mathrm{C}$, efetuou-se a segunda diluição, adicionando-se o diluidor II isotérmico, na mesma proporção do diluidor I, seguida da terceira avaliação da motilidade e do vigor espermático. Após essas avaliações, as amostras foram submetidas à estabilização em $4,0^{\circ} \mathrm{C}$ durante o período de uma hora. Concluída a estabilização, procede-se uma quarta avaliação da motilidade e do vigor espermático antes do envase (E) de cinco palhetas de $0,5 \mathrm{~mL}$, previamente identificadas de acordo com o respectivo tratamento de cada repetição. Essas palhetas foram seladas com álcool polivinílico e depositadas sobre um suporte flutuante, o que permitiu sua exposição horizontal ao vapor de nitrogênio líquido (N2) a uma altura de $3,5 \mathrm{~cm}$ durante 20 minutos. Após esse período, as palhetas foram depositadas diretamente no N2, onde foram acondicionadas em raques e armazenadas em botijão criogênico a 196oC. O processo de descongelamento foi realizado em banho-maria a $37^{\circ} \mathrm{C}$ (SILVA et al., 1998), seguido da quinta avaliação da motilidade e do vigor espermático e das alterações morfológicas, executada em preparação úmida sob microscopia de contraste de fase ( objetiva 100X), tendo sido contadas 200 células por amostra. O delineamento experimental foi $\mathrm{o}$ de blocos ao acaso com quatro repetições, sendo o animal o critério de bloqueamento. As análises estatísticas incluíram a análise de variância e o "Teste F". Diferenças significativas a 5\% ensejaram a aplicação do "Teste de Tukey" para a classificação das médias no mesmo nível de significância. As variáveis motilidade no sêmen fresco, após a adição do diluidor I e do diluidor II, antes do envase e após o descongelamento, bem como vigor, após o descongelamento foram analisadas depois de sofrerem a transformação Raiz Quadrada. Os defeitos morfológicos primários, secundários e totais no sêmen fresco e os defeitos morfológicos primários no sêmen descongelado também passaram pelo mesmo processo de transformação. Organizaram-se os dados referentes à morfologia espermática num esquema fatorial 4 x 2 (4 substâncias testadas $\mathrm{x}$ morfologia espermática do sêmen fresco e descongelado). Para a análise dos dados, empregou-se o pacote estatístico SAS (SAS, 1988).

\section{RESULTADOS}

As características da fração espermática dos ejaculados são apresentados na tabela 1. Dentro dos parâmetros considerados normais para a espécie, citados por BURKE (1986) os valores encontrados são excelentes para a raça utilizada no experimento. $\mathrm{Na}$ tabela 2, são apresentados os defeitos morfológicos no sêmen descongelado, sendo avaliados conforme citado por BURKE (1986). O acompanhamento da motilidade e do vigor espermático, durante todas as etapas do processo de congelamento, permitiu avaliar a influência dos crioprotetores etileno glicol nas concentrações de 0,25, 0,50 e $1 \mathrm{M}$, e do glicerol 0,8 M (controle).

$\mathrm{Na}$ figura 1, são demonstrados os resultados de motilidade nas diferentes fases do processo de

Tabela 1 - Características das frações espermáticas de quatro cães da raça Pastor Alemão utilizados no experimento, representados por valores mínimos, média \pm erro padrão da média $(E P M)$ e valores máximos $(n=10$ ejaculados).

\begin{tabular}{lccc}
\hline Parâmetros Avaliados & Mínimo & Média & Máximo \\
\hline Volume da $2^{\circ}$ fração (ml) & 0,5 & $1,05 \pm 0,12$ & 2,0 \\
Concentração espermática $\left(\mathrm{x} 10^{6} / \mathrm{mm}^{3}\right)$ & 0,34 & $0,58 \pm 0,07$ & 1,05 \\
Número total de espermatozóides $\left(\mathrm{x} 10^{6} / \mathrm{ml}\right)$ & 262,50 & $597,25 \pm 79,72$ & 1050 \\
Motilidade (\%) & 90 & $93,75 \pm 0,63$ & 95 \\
Vigor (0-5) & 5 & $5,00 \pm 0,00$ & 5 \\
Defeitos morfológicos primários (\%) & 5 & $10,87 \pm 0,24$ & 18 \\
Defeitos morfológicos secundários (\%) & 4 & $10,93 \pm 0,26$ & 24 \\
Defeitos morfológicos totais (\%) & 6 & $21,80 \pm 0,30$ & 35 \\
\hline
\end{tabular}


Tabela 2 - Valores médios de alterações morfológicas espermáticas no sêmen canino pós descongelamento. (média \pm erro padrão da média).

\begin{tabular}{llll}
\hline Crioprotetores & $\begin{array}{l}\text { Defeitos morfológicos } \\
\text { primários (\%) }\end{array}$ & $\begin{array}{l}\text { Defeitos morfológicos } \\
\text { secundários (\%) }\end{array}$ & $\begin{array}{l}\text { Defeitos morfológicos } \\
\text { totais (\%) }\end{array}$ \\
\hline${ }^{*} E G(0,25 M)$ & $5,00 \pm 0,81^{\mathrm{a}}$ & $18,75 \pm 2,86^{\mathrm{ab}}$ & $23,75 \pm 3,19^{\mathrm{a}}$ \\
${ }^{*} E G(0,50 M)$ & $6.25 \pm 1,79^{\mathrm{a}}$ & $19,75 \pm 2,17^{\mathrm{ab}}$ & $26,00 \pm 3,87^{\mathrm{a}}$ \\
${ }^{*} E G(1 M)$ & $4,50 \pm 2,02^{\mathrm{a}}$ & $13,50 \pm 3,27^{\mathrm{b}}$ & $18,00 \pm 5,21^{\mathrm{a}}$ \\
${ }^{*} G L$ & $8,00 \pm 3,24^{\mathrm{a}}$ & $26,00 \pm 4,06^{\mathrm{a}}$ & $34,00 \pm 7,14^{\mathrm{a}}$ \\
\hline
\end{tabular}

${ }^{\text {abc }}$ Médias seguidas de letras diferentes no mesma coluna, são significativamente diferentes entre si pelo Teste de Tukey $(\mathrm{p}<0,05)$.

*EG (Etileno glicol), GL (glicerol).

congelamento. Não foram observadas diferenças estatísticas quanto à motilidade no sêmen fresco, após a adição do diluidor I e do diluidor II. Ao envase, as concentrações de 0,25 e $0,50 \mathrm{M}$ de etileno glicol e de $0,8 \mathrm{M}$ de glicerol não apresentaram diferenças quanto à motilidade quando comparadas entre si, em todas as etapas, no entanto, 0,25 e $0,50 \mathrm{M}$ de etileno glicol tiveram maior concentração de $1 \mathrm{M}$, a qual apresentou resultados semelhantes ao glicerol. No descongelamento, não se observaram diferenças entre os grupos etileno glicol e glicerol quando comparados entre si.

O vigor espermático do sêmen, demonstrado ao longo do processo de congelamento e visualizado na figura 2, demonstrou não haver diferenças entre os grupos no sêmen a fresco e na adição do diluidor I. Após a adição do diluidor II, não houve diferenças entre as concentrações de 0,25 , $0,50 \mathrm{M}$ de etileno glicol, sendo que as mesmas foram semelhantes ao controle $(0,8 \mathrm{M}$ de glicerol), mas diferiram da concentração de $1 \mathrm{M}$, a qual se mostrou semelhante ao controle.

Ao envase, o vigor nos grupos $0,25 \mathrm{e}$ $0,50 \mathrm{M}$ de etileno glicol, foi similar. No entanto, ambos os grupos foram superiores ao vigor dos grupos $0,8 \mathrm{M}$ de glicerol e $1 \mathrm{M}$ de etileno glicol. Após o descongelamento, as diferenças encontradas entre os grupos no vigor espermático, foram semelhantes às acima descritas, não apresentando diferenças entre si, mas se mostrando superiores às concentrações de $0,8 \mathrm{M}$ de glicerol e $1 \mathrm{M}$ de etileno glicol.

A avaliação dos defeitos morfológicos totais no pós-descongelamento demonstrou não haver diferenças entre as diferentes concentrações de etileno glicol testadas quando comparadas entre si e com o crioprotetor controle (glicerol).

\section{DISCUSSÃO}

Os valores observados nas tabela 1 demonstram que os ejaculados se encontravam dentro dos padrões fisiológicos da espécie, segundo CHRISTHIANSEN (1986) e, portanto, estavam aptos a serem utilizados no experimento. A avaliação da motilidade do sêmen antes do envase, demonstrado na figura 1 , demonstrou a ocorrência de uma menor motilidade espermática na concentração de $1 \mathrm{M}$ de etileno glicol. Tal fato ratifica os resultados obtidos por RODRIGUES \& RODRIGUES (1998), os quais observaram que ao adicionarem o crioprotetor glicerol ao sêmen canino pré-diluído ocorria uma diminuição acentuada da motilidade progressiva dos espermatozóides. Apesar da diferença observada entre os tratamentos na avaliação espermática antes do envase, essa variação não ficou evidenciada nos tratamentos após o descongelamento. Resultados semelhantes foram obtidos por MORAES et al. (1998) que, congelando sêmen ovino com $0,50 \mathrm{M}$ de etileno glicol, notaram uma manutenção da motilidade semelhante a do glicerol (0,72M), e por ALVARENGA et al. (2000) que, ao congelarem sêmen eqüino, não observaram diferenças entre a utilização de glicerol e etileno glicol.

A inexistência de variações no vigor espermático (Figura 2) no sêmen fresco deve-se à qualidade dos ejaculados usados no experimento. No entanto, a manutenção desse vigor, após a adição do diluidor I, ocorreu em razão do fornecimento de um substrato energético para os espermatozóides. Após a adição do diluidor II, houve um decréscimo significativo no vigor espermático das concentrações de $0,8 \mathrm{M}$ de glicerol e $1 \mathrm{M}$ de etileno glicol. Isso pode ter ocorrido em função da alteração da osmolaridade (FARSTAD, 1996), e da ação do agente crioprotetor sobre os espermatozóides, bem como do seu efeito tóxico relatado por MORAES et al. (1998) que observaram um pior desempenho do etileno glicol na concentração de 0,7M. McLAUGHLIN et al. (1992) descreve os efeitos tóxicos do glicerol sobre os espermatozóides, fato que ocorre provavelmente em função da interação molecular do glicerol com a membrana plasmática dos espermatozóides, alterando sua fluidez pela intercalação na dupla camada lipídica, o que modifica a viscosidade citoplasmática e, dessa maneira, afeta todas as reações metabólicas (HAMMERSTEDT \& GRAHAN, 1992).

A avaliação dos defeitos morfológicos totais no sêmen descongelado entre as concentrações testadas demonstrou haver semelhanças entre os 


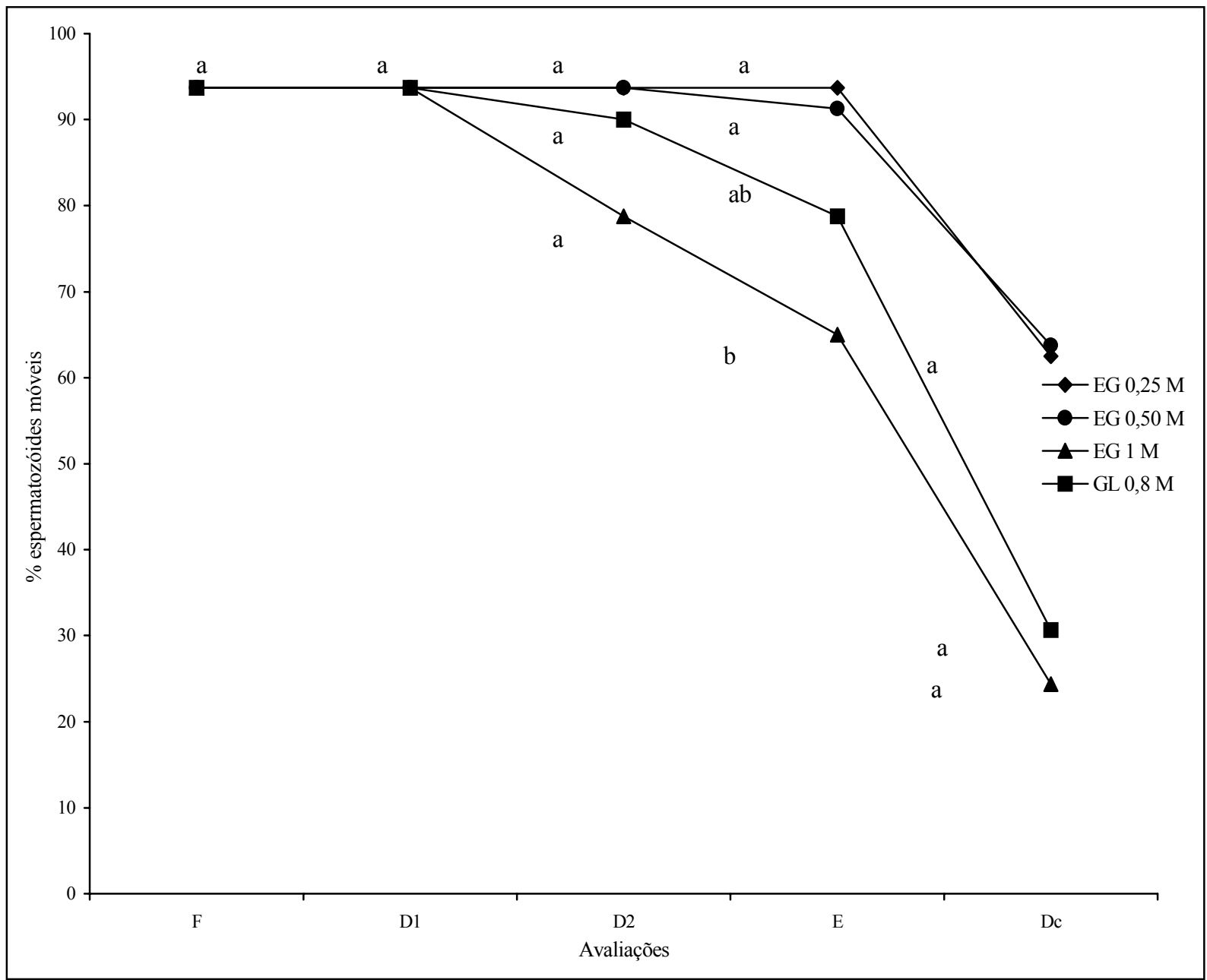

Figura 1 - Porcentagem de espermatozóides móveis no sêmen canino fresco (F) após a primeira diluição (D1), segunda diluição (D2), no momento do envase (E) e no descongelamento (Dc), empregado diferentes concentrações de etileno glicol (EG) e glicerol (GL) como crioprotetor.

${ }^{\mathrm{a}, \mathrm{b}}$ Letras diferentes na mesma avaliação implicam diferenças estatísticas pelo Teste de Tukey $(\mathrm{P}<0,05)$.

tratamentos testados. Resultados semelhantes foram obtidos por PEÑA et al. (1998), avaliando os danos acrossomais de espermatozóides congelados com glicerol pela técnica de coloração nigrosina-eosina. Os autores observaram manutenção de elevadas porcentagens de espermatozóides com acrossoma intacto. Entretanto, RODRIGUEZ-MARTINEZ et al. (1993) observaram que, apesar de uma aparente manutenção da morfologia acrossomal, na microscopia eletrônica de transmissão foram verificadas perdas de conteúdo e vesiculação das membranas acrossomais após o descongelamento. Esse fato pode justificar a baixa percentagem de anormalidades acrossomais, usualmente relatadas quando usada microscopia de contraste de fase. Somente uma análise por microscopia eletrônica, ou com sondas fluorescentes ou corantes como a clortetraciclina possibilitaria uma observação mais detalhada dos espermatozóides criopreservados pelas concentrações testadas, o que definiria qual a melhor concentração a ser empregada.

\section{CONCLUSÕES}

O etileno glicol nas concentrações de $0,25,0,50$ e $1 \mathrm{M}$. é um crioprotetor que pode substituir o glicerol em diluentes à base do trisgema.

\section{AGRADECIMENTOS}

Ao Canil Vento Divino da Base Aérea de Santa Maria (BASM) pela cedência dos animais. 


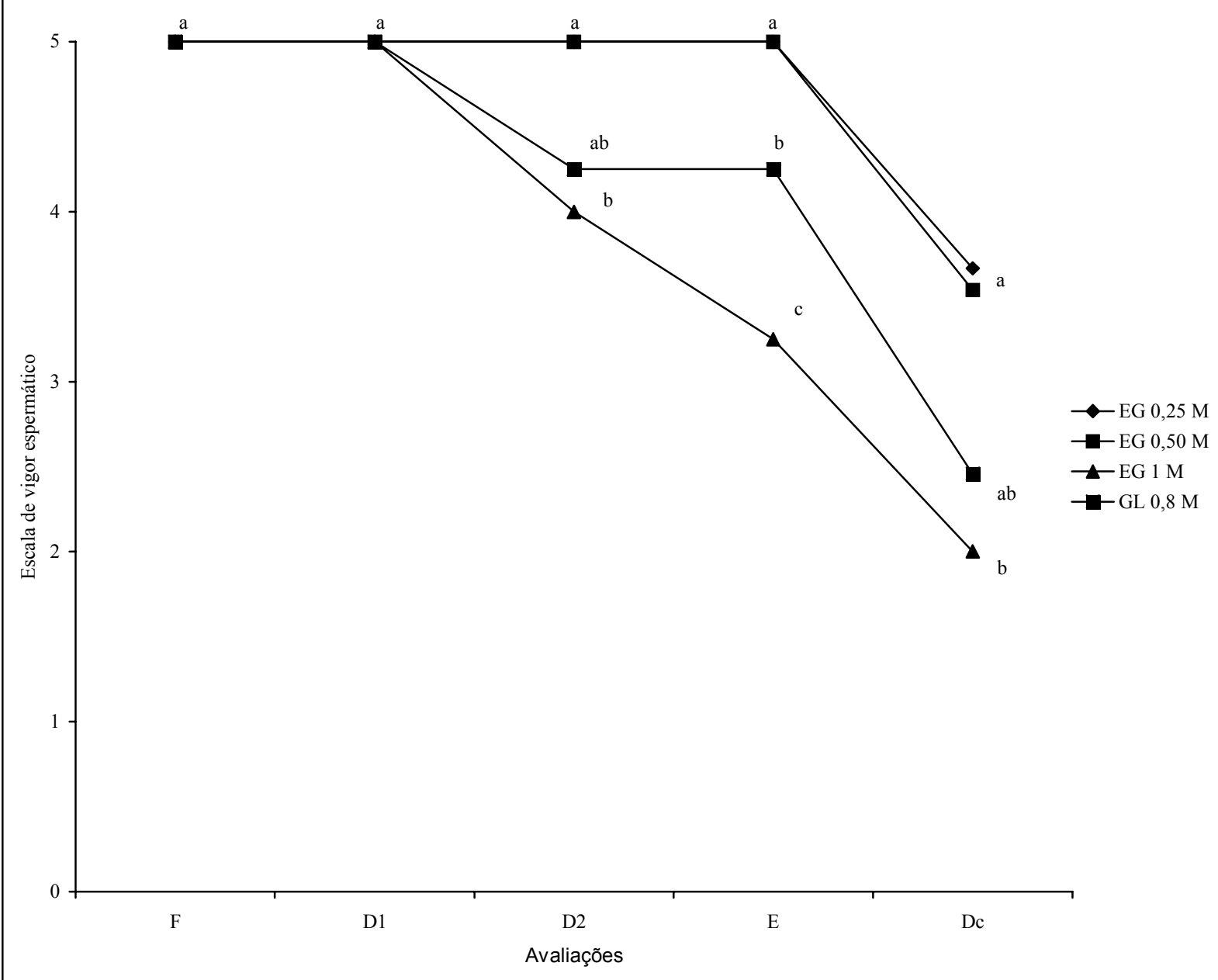

Figura 2 - Vigor espermático no sêmen canino fresco (F) após a primeira diluição (D1), segunda diluição (D2), no momento do envase (E) e no descongelamento (Dc), empregando diferentes concentrações de etileno glicol (EG) e glicerol (GL) como crioprotetor. ${ }^{\mathrm{a}, \mathrm{b}, \mathrm{c}}$ Letras diferentes na mesma avaliação implicam diferenças estatísticas pelo Teste de Tukey $(\mathrm{P}<0,05)$.

\section{FONTES DE AQUISIÇÃO}

a Sigma Chemical Company. St. Louis. Mo. USA.

\section{REFERÊNCIAS BIBLIOGRÁFICAS}

ALVARENGA, M.A., LANDIM-ALVARENGA, F.C., MOREIRA, R.M., et al. Acrosomal ultrastructure of stallion spermatozoa cryopreserved with ethylene glycol using two packaging systems. Equine Veterinary Journal, v.32, n.6, p.541-545, nov, 2000 .

BURKE, T.J. Small animal reproduction and infertility. A clinical approach to diagnosis and treatment. Philadelphia : Lea \& Febiger, 1986. p.210-211.

CHRISTIANSEN, I.J. Reprodução no cão e no gato. São Paulo : Manole, 1986. 363p.

ENGLAND, G.C. W., PONZIO, P. Comparasion of the quality of frozen-thawed and cooled-rewarmed dog semen. Theriogenology, v.46, p.165-171, 1996.
FARSTAD, W. Semen cryopreservation in dogs and foxes. Animal Reproduction Science, v.42, p.251-260, 1996.

FARSTAD, W. Assisted reproductive technology in canid species. Theriogenology, v.53, p.175-186, 2000.

FELDMAN, E.D, NELSON, R.C. Clinical and diagnostic evaluation of male reproductive tract. In: FELDMAN, E.D; NELSON, R.C. Canine and feline endocrinology and reproduction. Philadelphia : Saunders, 1996. p.673-690.

HAMMERSTEDT, R.H., GRAHAN, J.K. Cryopreservation of mammalian sperm: the enigma of glicerol. Cryobiology, v.29, p.26-38, 1992 .

McLAUGHLIN, E.A., FORD, W.C.L., HULL, M.G.R. The contribution of the toxity of a glycerol-egg yolk-citrate cryopreservative to the decline in human sperm motility during cryopreservation. Journal of Reproduction and Fertility, v.95, p.749-754, 1992. 
MERCANTE, C.F.J., ARRUDA, R.P., NEVES NETO, J.R., et al Congelação de sêmen equino em etileno glicol ou glicerol: motilidade, vigor e teste de termoressistência. In: CONGRESSO BRASILEIRO DE REPRODUÇÃO ANIMAL, 1995. Anais... Belo Horizonte, MG : Congresso Brasileiro de Reprodução Animal, 1995. p.290.

MORAES, C.N., NEVES, J.P., GONÇALVES, P.B.D., et al. Criopreservação do sêmen ovino em pellets com etileno glicol. Ciência Rural, Santa Maria, v.28, n.2, p.287-292, 1998.

NEVES NETO, J.R., MERCANTE, C.F.J., ARRUDA, R.P., $\boldsymbol{e}$ al.. Fertilidade do sêmen equino congelado com etilenoglicol ou glicerol. In: CONGRESSO BRASILEIRO DE REPRODUÇÃO ANIMAL, 1995, Belo Horizonte - MG. Anais... Minas Gerais : Congresso Brasileiro de Reprodução Animal, 1995. p.292.

PEÑA, A.I., BARRIO, F., QUINTELA, L.A., et al. Effect of different glycerol treatment on frozen-thawed dog sperm longevity and acrossomal integrity. Theriogenology, v.50, p.163-174, 1998 .

PLATOV, E.M. The freezing of ram semen in a lactose-yolk ethileneglycol diluent. Animal Breeding Abstract, p.76-77, 1965.

PLATZ, C.C., SEAGER, S.W.J. Successful pregnancies with concentrated frozen canine semen. Laboratory Animal Science, v.27, n.6, p.1013-1016, 1977.
RODRIGUES, B.A.; RODRIGUES, J.L. Efeito da adição de diferentes concentrações de albumina sérica bovina (BSA) ao diluidor à base de tris sobre a viabilidade in vitro do sêmen canino criopreservado. Arquivos da Faculdade de Veterinária da UFRGS, Porto Alegre, v.26, n.2, p.32-49, 1998.

RODRIGUEZ-MARTINEZ, H., EKWALL, H., LINDEFORSBERG, C. Fine structure and elemental composition of fresh and frozen dog spermatozoa. Journal of Reproduction and Fertility. v.47 (Suppl.), p.279-285, 1993.

SALAMON, S., MAXWELL, W.M.C. Frozen storage of ram semen I. Processing, freezing, thawing and fertility after cervical insemination. Animal Reproduction Science, v.37, p.185-249, 1995.

SAS. Statistical Analysis System, 6.03ed. Cary, NC, USA : SAS Institute INC, 1988. 1028p.

SEAGER S.W.J. Artificial Insemintion in dogs. In: BURKE, T.J. Small animal reproduction and infertility: A clinical approach to diagnosis and treatment. Philadelphia : Lea \& Febiger, 1986. Cap.3, p.207-217.

SILVA, A.R., CARDOSO, R.C.S., SILVA, L.D.M. Efeito do processo de descongelação sobre a viabilidade do sêmen canino in vitro. Ciência Animal, v.8, n.2, p.75-80, 1998. 